\title{
DeSign Solution of SEMI-Automatic LiNEAR LOADING MEASUREMENT LINE
}

\author{
RISOVIC, S.; ZEZELJ, D. \& PANIC, N.
}

Abstract: This work presents a design solution of semi-automatic measurement line that would provide more accurate results and increase the speed of the recalibrating process of the torque tools. Tools considered here are operated by hand and thus subjected to the performance (skill, strength and knowledge) of the operator. Since the pulling speed and the force are difficult to maintain or repeat, the results differ from the expected values. The analysis filtered out the solution with gearbox and trapezoidal spindle which is taken as the base for the prototype line to be produced. The prototype was tested and has shown enhanced repeatability of the measurement, ease of operation and suitability for implementing automation features. Additional analyses regarding kinematics and force distribution were performed in order to complete the design evaluation and to prove the usability for the intended purpose.

Key words: torque, tools, measurement, bending, friction
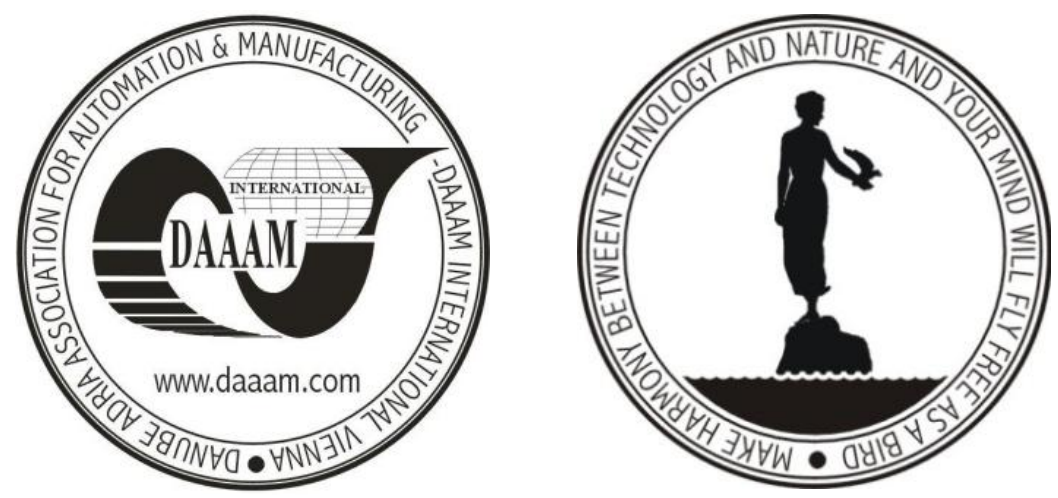

Authors' data: Univ. Prof. Dr. Sc. Risovic, S[tjepan]*; Dr. Sc. Zezelj, D[ragan]**; Panic, N[enad]**, Mech. Eng., * University of Zagreb, Faculty of Forestry, Svetosimunska 2, 10000, Zagreb, Croatia, ** University of Zagreb, Faculty of Mechanical Engineering and Naval Architecture, Ivana Lucica 5, 10000, Zagreb, Croatia, srisovic@sumfak.hr, dzezelj@fsb.hr, npanic@fsb.hr

This Publication has to be referred as: Risovic, S[tjepan]; Zezelj, D[ragan] \& Panic, N[enad] (2010). Design Solution of Semi-Automatic Linear Loading Measurement Line, Chapter 60 in DAAAM International Scientific Book 2010, pp. 687-696, B. Katalinic (Ed.), Published by DAAAM International, ISBN 978-3901509-74-2, ISSN 1726-9687, Vienna, Austria

DOI: $10.2507 /$ daaam.scibook.2010.60 


\section{Introduction}

Torque tools are used in everyday life by machine operators, car mechanics, steel construction workers, dentists, and many others. They differ in the working principles and load ranges and therefore, in design, size and accuracy. According to the ISO 6789 they are divided into two groups: indicating and setting torque tools. While indicating tools are intended to indicate torque exerted by the tool at the output drive, the purpose of the setting torque tools is to exert the prescribed value of the torque followed by appropriate signal. General use of the setting tools is to set the desired amount of axial force into a screw or bolt joint. The connection between the introduced torque and the achieved force is complex, though often reduced to only a few parameters on account of simplicity of calculation (Decker, 1975). However, the basic assumption that must be met to even approximately achieve the desired force is that the torque tool exerts the prescribed value of torque within the limits of acceptable tolerance as stated in ISO 6789. In order to provide such performance, torque tools must be recalibrated periodically. The focus of this work is on the recalibration procedure of the setting torque tools that should be conducted by a certified calibration laboratory and the appropriate equipment that should be used.

\section{Existing measurement line}

The measurement line (Fig. 1) consists of the standardized tool driving square adapter (2) mounted on the top flange of the measurement shaft (1). Four strain gages forming full bridge are attached to the outside diameter in the middle of the shaft and connected to the digital measurement acquisition system (3). The last item in the line is a PC with software compatible to the acquisition system (4).

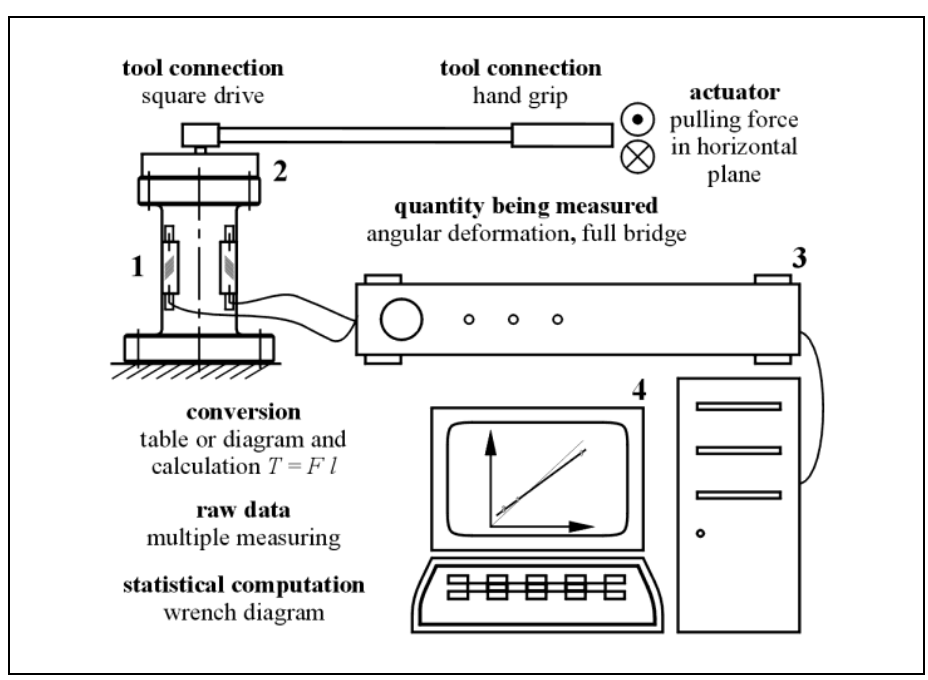

Fig. 1. Existing measurement line

\subsection{Measurement procedure}

The measurement procedure (Schicker \& Wegener, 2002; ISO 6789) is conducted by hand pulling the torque tool mounted on a driving square attached to the top of the measurement shaft (Fig. 1). Due to angular deformation of the shaft 
electrical resistance of gages is changed and picked up by the acquisition system in the form of electrical potential change. Those changes are recorded continuously by PC software as an array of discrete points (Figure 2a, b and c).

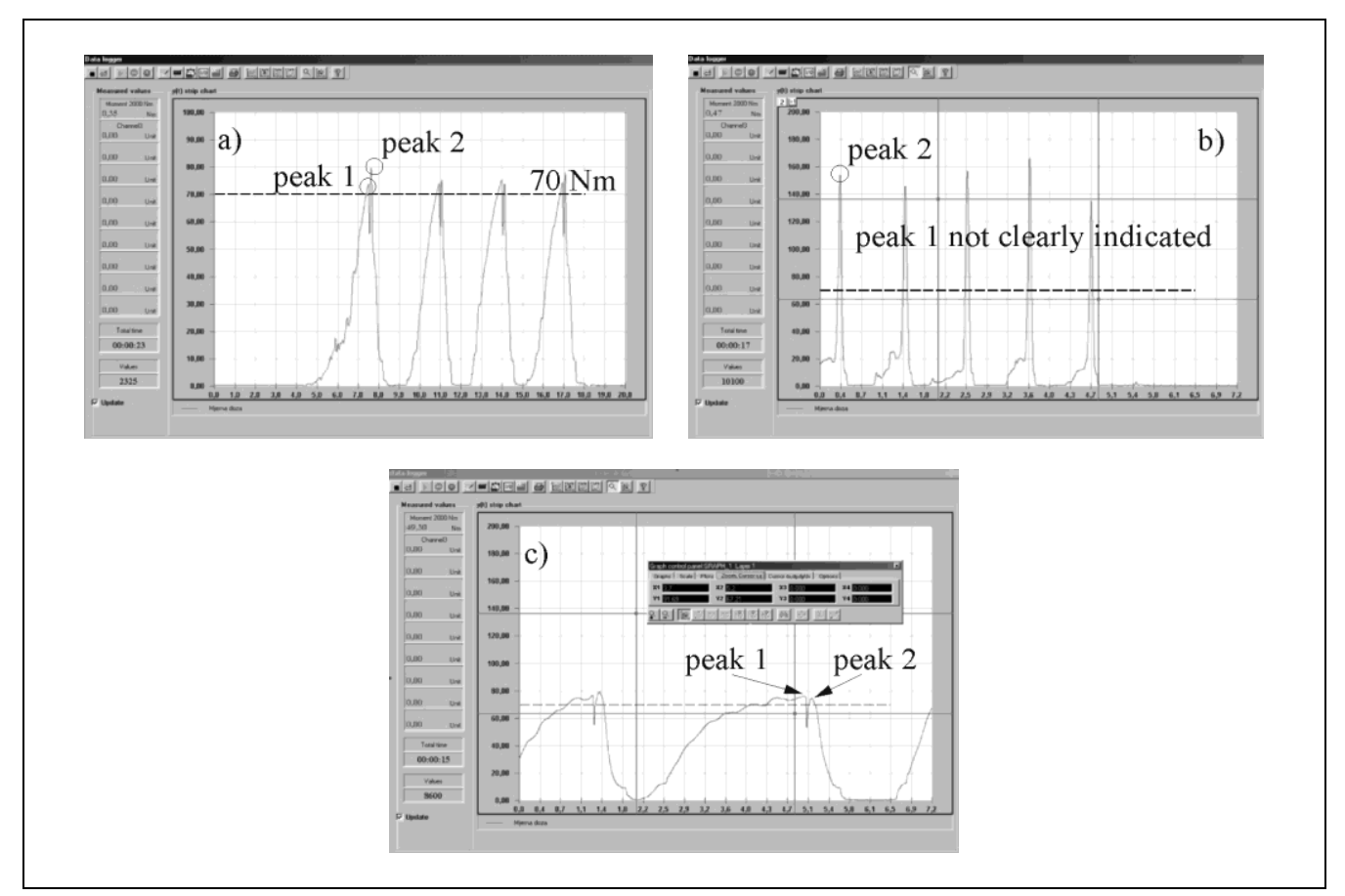

Fig. 2. Data recorded on hand pulling torque wrench set to 70Nm: a) normally, b) aggressively, c) smoothly

Fig. 2a shows the diagram obtained by usual operation, while $2 \mathrm{c}$ is achieved by smooth pulling with fine force increment. Fig. $2 b$ is the most important because of the lack of indication of tool triggering and also another peak that occurs when the tool mechanism hits the wrench casing allowing overload. Since the curves are not smooth and in cases $2 b$ and $2 c$ neither are they characteristic, they are not suitable for automated software processing.

It should be pointed out that the operating torque was set at $70 \mathrm{Nm}$ which should be considered as a small value, thus easy to handle. Wrenches designed for higher amounts of torque are usually robust, equipped with appropriate grip extension in order to provide less force on a larger distance for the operator to have better control over the force and the speed. However, the extension requires more space for manipulation forcing the operator to maintain control over a longer path leading back to the measurement inaccuracy.

\section{Improvement requests}

Operating performance has significant influence on the measurement accuracy as well as on the measurement repetition. In order to provide both, a new transmission device is considered, preferably electrically controlled with fine gradient adjustment. Instead of hand-pulling, the wrench would be driven by a new actuator while the measurement shaft would stay still (Fig. 3) (Opalic et al., 2004). The equipment must be suitable for operation in both directions to meet various tools 
capabilities. Modified measurement line must comply with requirements specified in ISO 6789, 2003. Additionally, since the measurement shaft is optimally designed for particular torque range, several shafts should be produced to cover at least the most usual ranges. The procedure should be kept simple without the need of changing measurement shafts, thus saving time in the preparation of measurement. Finally, because of better control of the input, smooth output diagrams could be created, suitable for automated processing. Therefore, a new program procedure for peak detection should be created and implemented in the existing software. On that basis, the coupling between software and the actuator could be created allowing semiautomatic operation within one measurement procedure.

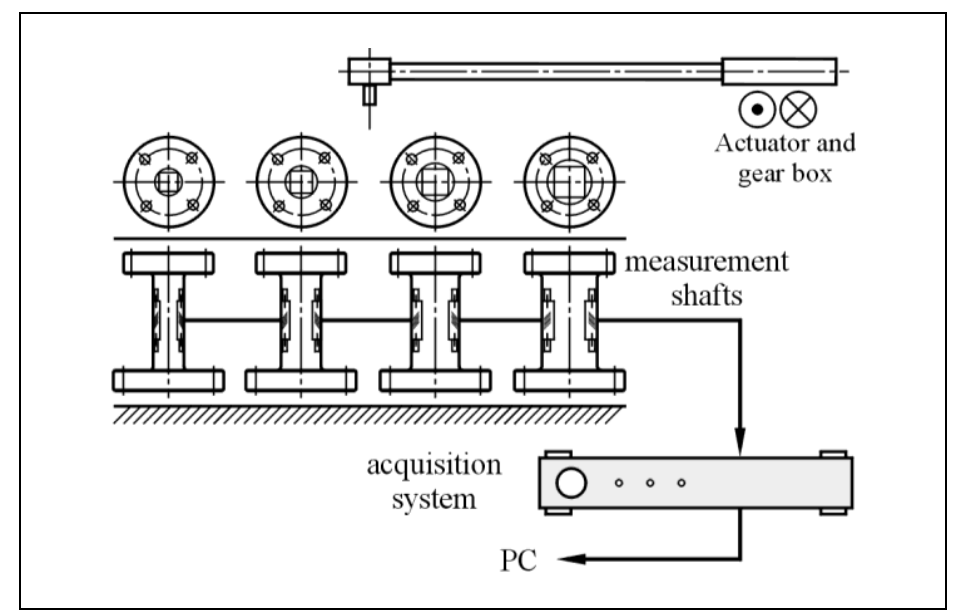

Fig. 3. Measurement line improvement design solution with actuator and transmission, additional shafts and software procedure (not shown)

\section{Results}

Based on the requested properties a prototype of a new, low-cost measurement line is produced (Fig. 4). Among the analysed design solutions the one with gearbox and trapezoidal spindle was chosen. The actuator and the transmission are chosen as compact product capable of both electrical and hand operation. The force is provided by transversal movement while adjustment in the longitudinal direction gives capability for testing various sizes of torque tools. The limiting load and the operating dimensions correspond to the tool with maximum torque value of $3000 \mathrm{Nm}$.
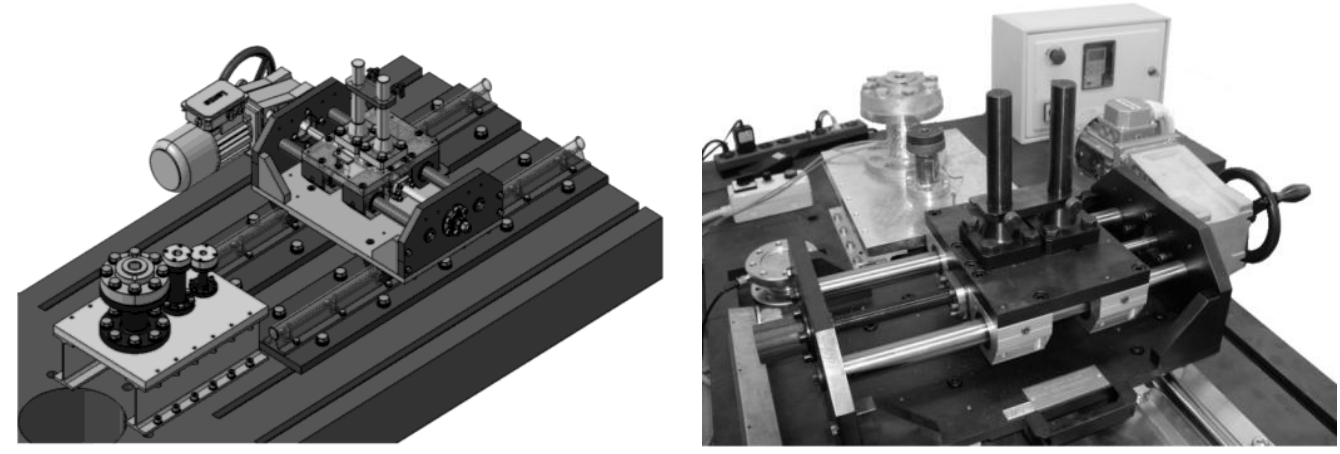

Fig. 4. Measurement line model (left) and the loading part of the prototype (right) 


\subsection{Relative uncertainty contribution of repeatability}

As mentioned before, the expected benefit of using machine loading is to reduce the operator's influence in the measurement procedure, particularly in the repetitive loading phase, and thus in the accuracy of results. In order to quantify this benefit testing was performed on one torque tool with three different amounts of torque and three different loading approaches: 1) machine loading, 2) careful loading performed by a trained operator and 3) aggressive loading. It is important that once the tool is adjusted and mounted on the top of the measurement shaft all loadings are carried out without dismounting or any other change or adjustment of any piece of the equipment for a particular torque value.

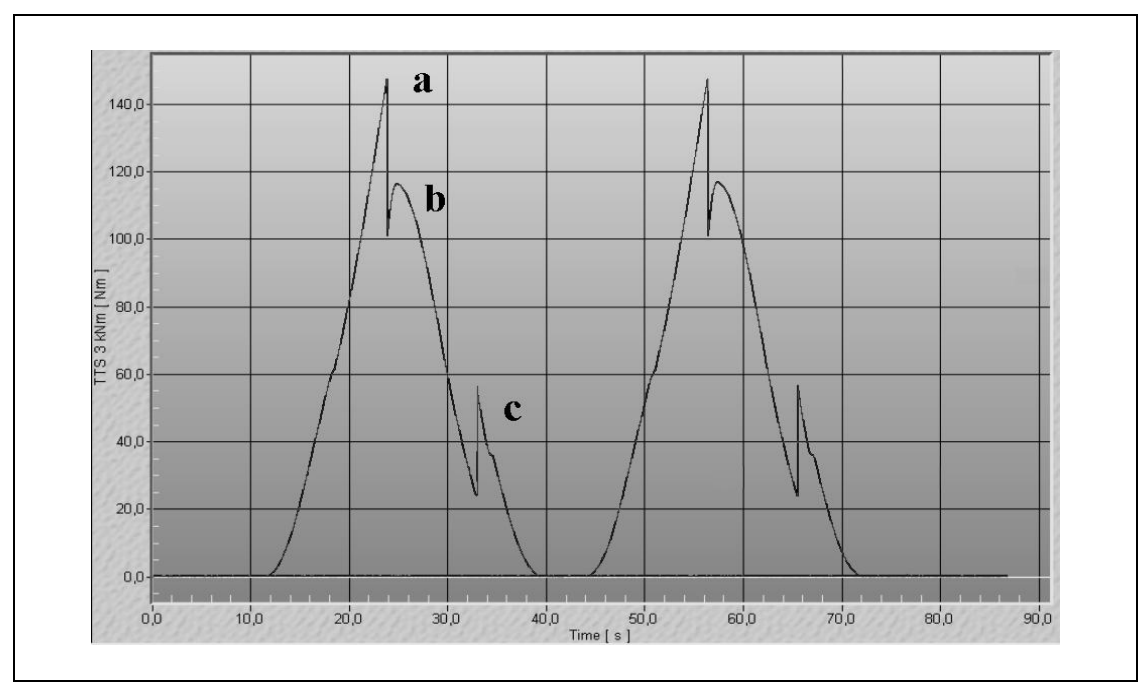

Fig. 5. Data acquisition results with modified measurement line

Testing of the prototype line was conducted for one setting torque tool with scale gradation of $5 \mathrm{Nm}$ at torque values of 50,140 and $230 \mathrm{Nm}$ according to ISO 6789. Figure 5 shows common diagrams plotted for two subsequent loading cycles on the basis of discrete points. On this enlargement scale one can conclude that there is no obvious difference between two consecutive measurements. The diagrams look practically identical and, what is most important, independent of the operator's physical and skill performance. Three significant moments could be clearly seen in each measurement cycle: a) main torque peak, b) secondary load due to mechanism impact with tool casing, and c) releasing of the mechanism allowing another operating cycle. Regardless of the fact that the investigated tool is capable of another loading cycle immediately after point c) the measurement shaft should be fully unloaded before it. Potential difference in the readings of the measurement shaft at zero loads before and after each cycle could be used to check if the equipment operates as expected.

Data for each measurement approach was recorded and processed. The adjusted and recorded values as well as the expected ones, presented in the form of absolute number and relative difference, are shown in Tables 1, 3 and 5 for the corresponding approaches. The expanded relative uncertainty of each measurement approach is calculated according to EURAMET/cg-14/v.01 and shown in Tables 2, 4 and 6. 
Risovic, S.; Zezelj, D. \& Panic, N.: Design Solution of Semi-Automatic Linear ...

\begin{tabular}{|c|c|c|c|c|c|}
\hline Steps, Nm & \multicolumn{5}{|c|}{ Indication in Nm } \\
\hline Steps, $\%$ & \multicolumn{5}{|c|}{ Exception from adjusted value \% } \\
\hline 50 & 52.32 & 52.20 & 52.02 & 51.90 & 51.90 \\
\hline 20.0 & 4.6 & 4.4 & 4.0 & 3.8 & 3.8 \\
\hline 140 & 145.94 & 145.94 & 145.82 & 145.70 & 145.70 \\
\hline 60.0 & 4.2 & 4.2 & 4.2 & 4.1 & 4.1 \\
\hline 230 & 240.93 & 240.92 & 240.32 & 240.26 & 240.14 \\
\hline 100.0 & 4.8 & 4.7 & 4.5 & 4.5 & 4.4 \\
\hline
\end{tabular}

Tab. 1. Approach 1 - Measurement results for machine loading

\begin{tabular}{|c|c|c|c|c|}
\hline $\begin{array}{c}\text { Steps, } \\
\mathrm{Nm}\end{array}$ & $\begin{array}{c}\text { Relative } \\
\text { uncertainty } \\
\text { contribution of } \\
\text { repeatability }\end{array}$ & $\begin{array}{c}\text { Uncertainty } \\
\text { contribution } \\
\text { of } \\
\text { resolution }\end{array}$ & $\begin{array}{c}\text { Relative } \\
\text { uncertainty } \\
\text { contribution of the } \\
\text { torque calibration } \\
\text { machine }\end{array}$ & $\begin{array}{c}\text { Expanded relative } \\
\text { uncertainty } \\
\text { of measurement in, } \\
(\mathrm{k}=2 ; \mathrm{P}=95 \%)\end{array}$ \\
\hline 50 & $\mathrm{wb}^{\prime}, \%$ & $\mathrm{wr}, \%$ & $\mathrm{wtcm}, \%$ & $\mathrm{w}, \%$ \\
\hline 140 & 0.57 & 2.89 & 0.01 & 8.24 \\
\hline 230 & 0.12 & 1.03 & 0.01 & 2.93 \\
\hline
\end{tabular}

Tab. 2. Approach 1 - Relative uncertainty for machine loading

\begin{tabular}{|c|c|c|c|c|c|}
\hline Steps, Nm & \multicolumn{5}{|c|}{ Indication in Nm } \\
\hline Steps, \% & \multicolumn{5}{|c|}{ Exception from adjusted value \% } \\
\hline 50 & 52.38 & 51.96 & 52.26 & 51.84 & 51.78 \\
\hline 20.0 & 4.8 & 3.9 & 4.5 & 3.7 & 3.6 \\
\hline 140 & 146.22 & 146.04 & 145.86 & 145.74 & 145.32 \\
\hline 60.0 & 4.4 & 4.3 & 4.2 & 4.1 & 3.8 \\
\hline 230 & 241.92 & 241.74 & 241.38 & 241.20 & 240.66 \\
\hline 100.0 & 5.2 & 5.1 & 4.9 & 4.9 & 4.6 \\
\hline
\end{tabular}

Tab. 3. Approach 2 - Measurement results for operator's manual loading

\begin{tabular}{|c|c|c|c|c|}
\hline $\begin{array}{c}\text { Steps, } \\
\mathrm{Nm}\end{array}$ & $\begin{array}{c}\text { Relative } \\
\text { uncertainty } \\
\text { contribution of } \\
\text { repeatability }\end{array}$ & $\begin{array}{c}\text { Uncertainty } \\
\text { contribution } \\
\text { of } \\
\text { resolution }\end{array}$ & $\begin{array}{c}\text { Relative } \\
\text { uncertainty } \\
\text { contribution of the } \\
\text { torque calibration } \\
\text { machine }\end{array}$ & $\begin{array}{c}\text { Expanded relative } \\
\text { uncertainty } \\
\text { of measurement in } \\
(\mathrm{k}=2 ; \mathrm{P}=95 \%)\end{array}$ \\
\hline 50 & $\mathrm{wb}^{\prime}, \%$ & $\mathrm{wr}, \%$ & $\mathrm{wtcm}, \%$ & $\mathrm{w}, \%$ \\
\hline 140 & 0.82 & 2.89 & 0.01 & 8.33 \\
\hline 230 & 0.44 & 1.03 & 0.01 & 3.04 \\
\hline
\end{tabular}

Tab. 4. Approach 2 - Relative uncertainty for operator's manual loading 


\begin{tabular}{|c|c|c|c|c|c|}
\hline Steps, Nm & \multicolumn{5}{|c|}{ Indication in Nm } \\
\hline Steps, \% & \multicolumn{5}{|c|}{ Exception from adjusted value \% } \\
\hline 50 & 52.39 & 52.32 & 52.27 & 51.09 & 50.90 \\
\hline 20.0 & 4.8 & 4.6 & 4.5 & 2.2 & 1.8 \\
\hline 140 & 146.43 & 145.40 & 146.28 & 146.17 & 145.57 \\
\hline 60.0 & 4.6 & 3.9 & 4.5 & 4.4 & 4.0 \\
\hline 230 & 240.99 & 241.89 & 241.52 & 240.65 & 239.70 \\
\hline 100.0 & 4.8 & 5.2 & 5.0 & 4.6 & 4.2 \\
\hline
\end{tabular}

Tab. 5. Approach 3 - Measurement results for aggressive manual loading

\begin{tabular}{|c|c|c|c|c|}
\hline $\begin{array}{c}\text { Steps, } \\
\mathrm{Nm}\end{array}$ & $\begin{array}{c}\text { Relative } \\
\text { uncertainty } \\
\text { contribution of } \\
\text { repeatability }\end{array}$ & $\begin{array}{c}\text { Uncertainty } \\
\text { contribution } \\
\text { of } \\
\text { resolution }\end{array}$ & $\begin{array}{c}\text { Relative } \\
\text { uncertainty } \\
\text { contribution of the } \\
\text { torque calibration } \\
\text { machine }\end{array}$ & $\begin{array}{c}\text { Expanded relative } \\
\text { uncertainty } \\
\text { of measurement in } \\
(\mathrm{k}=2 ; \mathrm{P}=95 \%)\end{array}$ \\
\hline 50 & $\mathrm{wb}^{\prime}, \%$ & $\mathrm{wr}, \%$ & $\mathrm{wtcm}, \%$ & $\mathrm{w}, \%$ \\
\hline 140 & 2.03 & 2.89 & 0.01 & 9.12 \\
\hline 230 & 0.50 & 1.03 & 0.01 & 3.08 \\
\hline
\end{tabular}

Tab. 6. Approach 3 - Relative uncertainty for aggressive manual loading

Comparative results for relative uncertainty contribution of repeatability for the investigated approaches are shown in Table 7 . What can be clearly seen is the significant difference between the first and the second cases ranging from 1.4 up to 3.7 times and even more between the first and the third ranging from 2.8 up to 4.2 times. Again, it should be noted that torque value of $230 \mathrm{Nm}$ is not to be considered as an amount causing significant problems for hand operation; yet, the repeatability could not be preserved compared to machine operation.II

\begin{tabular}{|c|c|c|c|}
\hline Steps, Nm & Approach 1, \% & Approach 2, \% & Approach 3, \% \\
\hline 50 & 0.57 & 0.82 & 2.03 \\
\hline 140 & 0.12 & 0.44 & 0.50 \\
\hline 230 & 0.23 & 0.37 & 0.64 \\
\hline
\end{tabular}

Tab. 7. Relative uncertainty contribution of repeatability for three investigated measurement approaches

\subsection{Design solution specifics}

Basically, every torque tool has to exhibit some rotational movement to produce torsion. Torque tools considered here operate while rotating around the axis of the joint being fastened. To simulate the same kinematics, a few basic design solutions of measurement lines are possible: either the torque tool rotates while the measurement shaft is fixed or vice versa. Both of them could be actuated by a linear or circular actuating device. Considering the nature of the joint fastening process, one can speculate that the most suitable design would be with circular actuation of the 
torque tool against a fixed measurement shaft. Yet, there are often other design solutions, perhaps because of their simplicity.

The measurement line considered in this work could be classified as a linear type corresponding to the movement of the loading device. Compared to the fastening process, this type has some drawbacks regarding kinematics and friction. This occurs because of different movements between the torque tool and the measurement shaft (Fig. 6). As can be seen, a part of the loading device (represented by a circle in Fig. 6) performs linear movement (path $\mathrm{p}_{\mathrm{LD}}$ ) while the torque tool rotates around the measurement shaft axis (path $\mathrm{p}_{\mathrm{TT}}$ ).

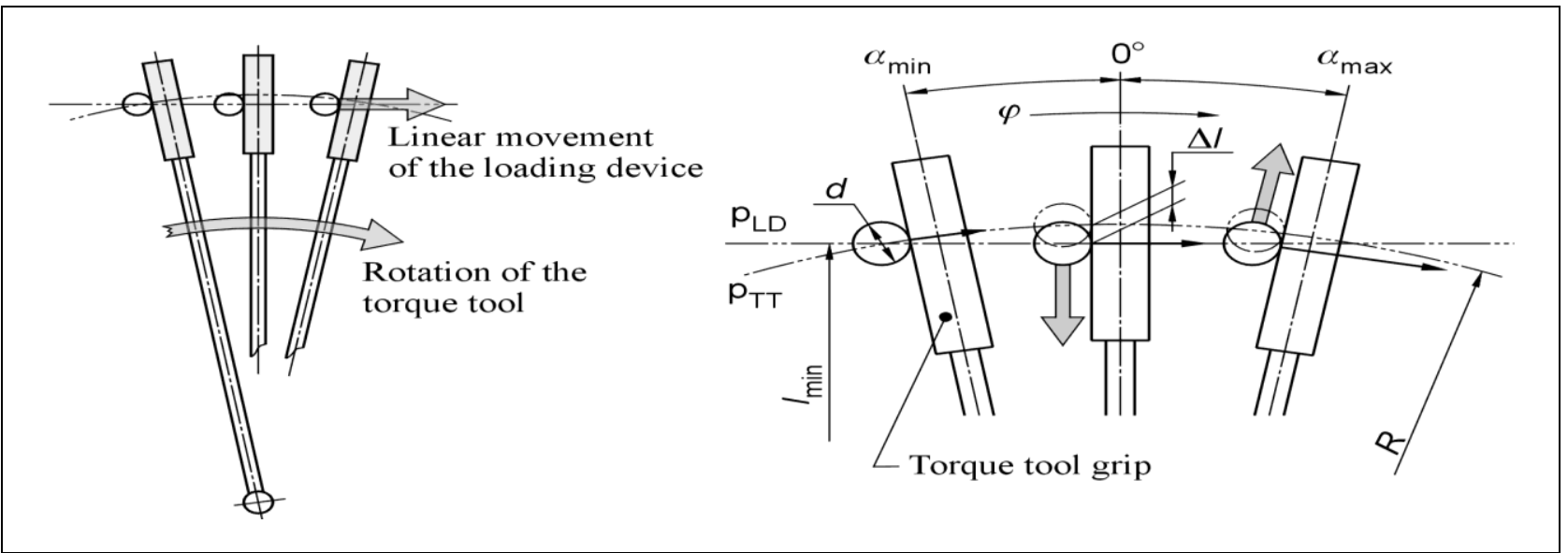

Fig. 6. Analysis of kinematics of the loading device and the torque tool

Because of this incompatibility in movement, the distance between the acting force and the measurement shaft axis changes continuously. Besides obvious difference there is small additional contribution due to the diameter of the cylinder part of the loading device (left in Fig. 7). This value continuously decreases this distance; thus the resulting distance is not symmetric regarding zero angle (right in Fig. 7).

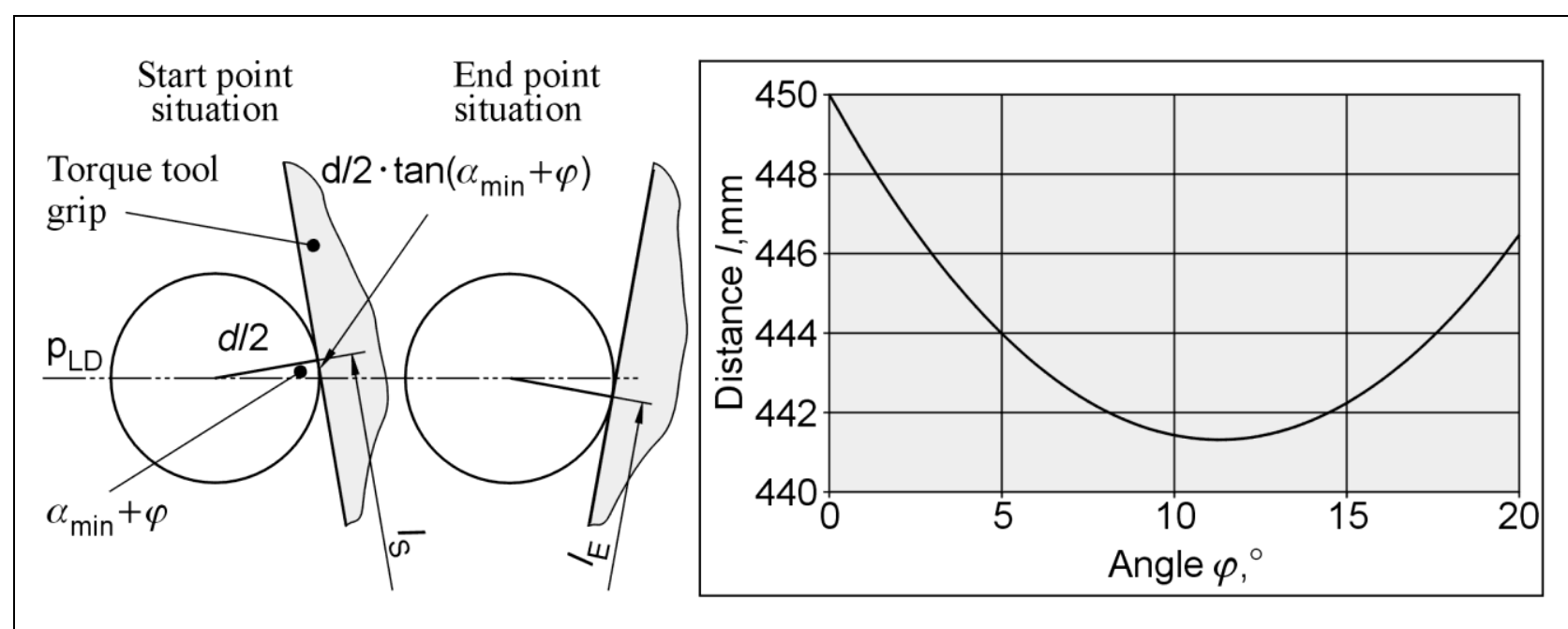

Fig. 7. Change of distance between acting force and measurement shaft for initial distance of $450 \mathrm{~mm}$, diameter of cylinder $20 \mathrm{~mm}$ and angle range from $-10^{\circ}$ to $+10^{\circ}\left(\varphi\right.$ from $0^{\circ}$ to $\left.20^{\circ}\right)$ 
Since the force needed to push the torque tool is conditioned by the angle of rotation which simultaneously drives changes in the force distance, it is obvious that the bending moment would change following the same pattern as the distance does. Moreover, because of the relative movement of the cylinder part under load and the grip of the torque tool, there comes to traction between them. This traction is influenced by angle of rotation in two ways. Firstly, since the force is conditioned by the angle the same is with traction. Secondly, the direction of traction changes at the zero angle (right in Fig. 6) or the corresponding $\varphi$ value of 10 degrees (right in Fig. 7). Before that value, the traction acts towards the measurement shaft (gray arrow aiming down, right in Fig. 6) and after it in the opposite direction (gray arrow aiming up, right in Fig. 6). The combined influence drives the change of both value and direction of the bending moment.

Besides the already mentioned, there is one more influence that should be taken into account concerning the torque tool hand grip. The torque tool hand grips are supplied in various designs: cross-roughed or with radial grooves mostly for aluminium parts and made of plastics or rubber to accommodate the operator. All designs have basically the same purpose - to prevent sliding while operating the tool. Various designs result in various friction coefficients between the cylinder part of the loading device and the grip ranging from 0.1 to even 0.8 . This could deliver unpredicted bending moment to the measurement shaft potentially causing its damage. For example, a combination of $1000 \mathrm{~N}$ pulling force with grip friction coefficient of 0.8 applied on $100 \mathrm{~mm}$ high measurement shaft could produce up to $21 \%$ higher amount of bending moment.

Extensive measurements have been conducted to approve or disapprove the mentioned influences. While the influence of the bending moment itself has proved to be compensated by the design of measurement shaft strain gages, type and layout, this was not the case with the influence of the amount of the traction force. This is probably due to the maximum permissible bending moment that was taken into account in the measurement shaft design and dimensioning. However, measurement shafts of delicate dimensions could be easily damaged if this influence was omitted.

\subsection{Automation sequence}

Another step in the improvement of the measurement line should be taken in order to automate some parts of the process. Suitability for implementing automation sequence can be easily estimated through the following points:

- readings from the digital measurement acquisition system are suitable for automated peak detection as well as accuracy control;

- equipment is electrically driven and electronically controlled;

- the software used allows user customization.

For this purpose the loop back control must be created between the actuator and the acquisition system or the PC allowing software to control the process (Figure 8). The measurement cycle could be then repeated as many times as needed, potentially determined by the data stored about a specific torque tool. If so, the operator's concern would be to mount the tool, set the torque value to be tested and introduce the tool type to the software. The rest of the work would be done by the system. 
Risovic, S.; Zezelj, D. \& Panic, N.: Design Solution of Semi-Automatic Linear ...

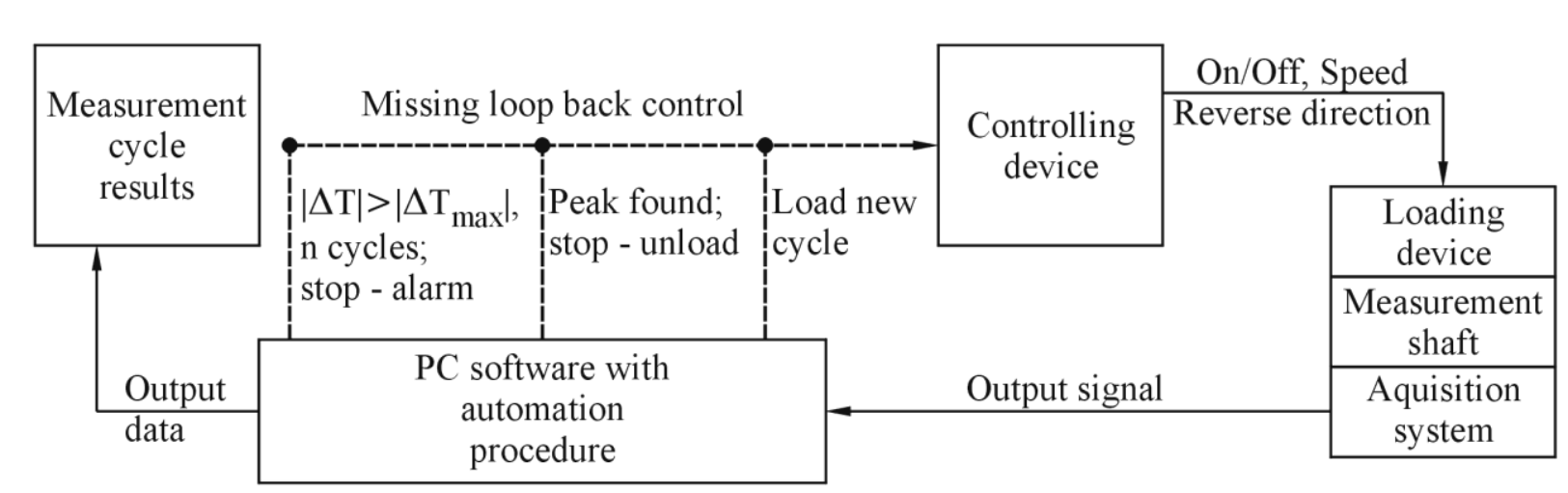

Fig. 8. Flowchart of a semi-automated process for one loading cycle

\section{Conclusion}

The undertaken analysis of the recorded data (Figure 2, Table 7) outlined the weaknesses of the old measurement line as follows:

- Accuracy of the measurement depends on the operator's physical performance.

- Output data do not form smooth curves, and thus are not suitable for automated peak detection.

Results show that the new prototype line offers benefits in both areas: discrete points form smooth curves whereas the repeatability of the measurement line is improved. Some drawbacks regarding linear loading are analyzed showing that the design of the processed tools could potentially impact the safety of the measurement shafts. Further work on the improvement will be focused on the development of the procedure for peak detection and automated operation within the measurement cycle.

This work was partially funded by the Croatian Ministry of Science, Education and Sports.

\section{References}

Decker, K.-H. (2007). Machinenelemente: Gestaltung und Berechnung, 16. Auflage, (Machine Parts: Desing and calculation, 16th Edition), C. Hanser Verlag, ISBN 3-446-19194-1, München

Opalic, M.; Veres, M. \& Zezelj, D. (2004). Measurement line design, Proceedings of 45th International Conference of Machine Design Departments, Mazal, P. (Ed.), pp. 78-83, ISBN 80-214-2702-7, Blansko, Czech Republic, September 2004, Brno University of Technology, Brno

Schicker, R. \& Wegener, G. (2002). Measuring torque correctly, Hottinger Baldwin Messtechnik, ISBN 3000089454, Bielefeld

***EURAMET/cg-14/v.01, Guidelines on the Calibration of Static Torque Measuring Devices (Previously EA-10/14), European Association of National Metrology Institutes, 2007

***ISO 6789:2003, Assembly tools for screws and nuts - Hand torque tools Requirements and test methods for design conformance testing, quality conformance testing and recalibration procedure, ISO, 2003 